\title{
Dermografismo Imediato Sintomático. Relato de caso
}

\author{
Symptomatic Immediate Dermography. Case report \\ Ricardo Henrique Schlaucher Richa†*, Maria Cristina Almeida de Souza§
}

\begin{abstract}
Resumo
Como citar esse artigo. Richa RHS, Souza MCA. Dermografismo Imediato Sintomático. Relato de caso. Revista de Saúde. 2018 Jan./Jun.; 09 (1): 18-21.

Dermografismo é uma forma de urticária física que pode chegar a acometer até $5 \%$ da população levando ao surgimento de lesões papulares e pruriginosas. Surge após estímulos físicos e é capaz de promover profundos impactos na qualidade de vida, pois pode se manifestar de forma grave com um quadro de angioedema. O quadro pode surgir em qualquer faixa etária, mas é mais frequente a partir da segunda década de vida. O sexo feminino é mais acometido. O diagnóstico é clínico, mas o pouco conhecimento sobre as dermopatias torna a sua identificação um desafio para os profissionais. $\mathrm{O}$ tratamento é simples, embora a cura possa não ser alcançada na maior parte dos casos. O caso de dermografismo imediato sintomático relatado neste artigo ratifica a relevância da atuação dos profissionais que atuam na Atenção Primária à Saúde no diagnóstico precoce e na adequada proposta terapêutica.

Palavras-chave: Angioedema; Urticária; Dermopatias.
\end{abstract}

\begin{abstract}
Dermographism is a form of physical urticaria that may be present in even $5 \%$ of the population leading to pruriginous papular lesions. It appears after physical stimulations and may cause deep impacts on the quality of life once it may appear as severe forms such as angioedema. This situation may manifest itself in any age group, but it is more frequent from the second decade of life. The female sex is more affected. The diagnosis is clinical, but the little knowledge about skin diseases makes the identification a challenge for professionals. The treatment is simple, although cure may be not reached in most cases. Symptomatic dermographism reported in this article ratifies the relevance of the performance of the professionals who work in Primary Health in the early diagnosis and adequate therapeutic proposal.

Keywords: Angioedema; Urticaria; Skin Diseases.
\end{abstract}

\section{Introdução}

Dermografismo, uma neurodermatose, também conhecido como urticária factícia, é um tipo de urticária física que acomete de $2 \%$ a $5 \%$ da população. As urticárias físicas são caracterizadas pelo desenvolvimento de lesões urticariformes e/ou de e por eritema transitório angioedema em áreas expostas da pele após aplicação de estímulos físicos tais como frio, pressão, vibração, calor e exposição solar, com consequente formação de pápulas - difusas ou localizadas. Urticária é uma dermatose frequente: de $15 \%$ a $20 \%$ da população têm pelo menos um episódio agudo desta doença em sua vida. Quando se arranha a pele destes pacientes com um material de ponta romba, aparece uma urticária, isolada, linear. O quadro pode se manifestar em qualquer faixa etária, mas é mais frequente a partir da segunda década de vida. O sexo feminino é mais acometido $1,2,3,4,5,6$.

As lesões de urticária apresentam-se de forma muito variável, porém em geral são pruriginosas, circunscritas, eritematopapulosas ou maculares, e usualmente regridem sem aspectos residuais. Cerca de $50 \%$ dos pacientes com urticária apresentam unicamente lesões urticarianas, $10 \%$ têm angioedema e $40 \%$, desenvolvem ambas as alterações. Urticária e angioedema podem ser decorrentes de estímulos antigênicos ou físicos, da ação direta de fármacos sobre células e/ou mediadores bioquímicos de reações de hipersensibilidade, de doenças sistêmicas, surgirem por mecanismos de autoimunidade e terem ainda etiologia idiopática. Podem ser classificados em agudos e crônicos, a depender do tempo de evolução. São considerados crônicos quando apresentam mais de 6 semanas de evolução. As formas agudas predominam em crianças e adultos jovens, enquanto as formas crônicas são mais observadas em adultos ${ }^{2,4,5,7,8}$.

O termo dermografismo vem do grego e significa "escrever na pele", pois quando se pressiona a pele com algo pontiagudo há o surgimento de marca (grafia na pele). As lesões são mais intensas à noite e costumam

Afiliação dos autores: † Discente do Curso de Graduação em Medicina da Universidade de Vassouras, Vassouras.RJ.

† Docente do Curso de Graduação em Medicina e do Mestrado em Ciências Aplicadas em Saúde. Universidade de Vassouras, Vassouras.RJ.

* Email para correspondencia: mcas.souza@uol.com.br 
estar associadas ao estresse, atividade física, uso de drogas, banhos quentes e escabiose ${ }^{2,3}$.

O dermografismo é classificado em: imediato simples, imediato sintomático, colinérgico e dermografismo tardio. Dermografismo imediato simples pode ser desencadeado após atrito provocado por objeto rombo, geralmente no antebraço ou no dorso provocando edema linear de $2 \mathrm{~mm}$ de largura ou mais, que desaparece em torno de 15 a 20 minutos após a pressão, sem prurido. Pacientes que manifestam esse tipo de quadro não necessitam de tratamento. Já no dermografismo imediato sintomático, que acomete principalmente no adulto jovem, existe prurido. $\mathrm{O}$ portador deste tipo de dermografismo tem como queixa típica a formação de pápulas lineares após o prurido, que costumam persistir por cerca de 30 minutos, sendo mais frequentes em áreas de pressão. $\mathrm{O}$ dermografismo tardio é raro e se caracteriza por resposta normal ou dermográfica imediatamente após a riscadura da pele, persistindo por 30 minutos. Depois de 3 a 8 horas surge então edema linear, profundo, com sensação de queimação, durando em média 24 a 48 horas. O diagnóstico do dermografismo é feito pela realização de pressão na pele com um material de ponta romba ou por um dermografômetro com pressão de $36 \mathrm{~g} / \mathrm{mm}^{2,4,5}$.

Geralmente o dermografismo não possui cura. Sintomas podem ser amenizados, porém a reincidência é frequente. Não costuma apresentar riscos elevados para a saúde dos portadores e a maior parte consegue conviver com os sintomas. O tratamento compreende tanto medidas farmacológicas como não farmacológicas. Quando necessária a prescrição de medicamentos, o anti-histamínico de primeira geração hidroxizina é uma das drogas de escolha, que pode ser associada a um antihistamínico de segunda geração em casos resistentes. Mas há diversidade de propostas terapêuticas na literatura. Os anti-histamínicos de primeira e segunda geração $\mathrm{H} 1$, hidroxizina e cetirizina, respectivamente, demonstraram melhora no controle sintomático. A associação de antagonistas H2 com antagonistas H1 não se mostrou benéfica no controle sintomático em estudos prévios. Terapia com luz ultravioleta B (UVB) também foi relatada com sucesso na terapia. A terapia tópica com uso de corticoesteróides pode melhorar os sintomas em urticárias tardias, mas tem uso limitado no tratamento de urticárias cutâneas difusas. O benefício é a diminuição dos mastócitos produtores de histamina; o seu fator limitador é o benefício temporário, revelandose menos eficaz para o tratamento de longo tempo em urticárias difusas ${ }^{6}$.

Há relato de uso de antidepressivo tricíclico cloridrato de doxepina de forma isolada ou associada a um anti-histamínico no controle dos sintomas do dermografismo ${ }^{2,6}$.

Em casos de urticária crônica não responsiva a anti-histamínicos, uma opção terapêutica é o uso de Dapsona, medicamento efetivo no tratamento de doenças que se caracterizam pelo acúmulo anormal de neutrófilos na pele ${ }^{8}$.

Este trabalho teve como objetivo relatar um caso de dermografismo imediato sintomático em uma paciente do sexo feminino, com foco no quadro clínico evolutivo.

\section{Relato de caso}

Paciente sexo feminino, 46 anos, parda, sem histórico de doença de base ou de doenças alérgicas. Relatou durante uma Visita Domiciliar (VD), a presença de lesões na pele da região dos antebraços direito e esquerdo, acompanhadas de intensa coceira, que haviam surgido há cerca de 3 meses. As lesões eram intermitentes, com períodos de remissão. As lesões na pele surgiam e se intensificavam após banhos quentes e prolongados. Paciente negou histórico familiar de lesões dermatológicas. Informou que o hábito de coçar o local das lesões promovia um alívio momentâneo, mas que minutos após o prurido retornava de forma mais intensa.

Ao exame físico, constataram-se lesões dermatológicas indolores, bem delimitadas, de caráter pruriginoso, com vermelhidão, em diversas regiões corporais, com destaque para aquelas nas regiões de dobras cutâneas e nas de contato com vestimenta, principalmente na região de antebraços (Figura 1), fossa ilíaca esquerda e na região escapular baixa esquerda e em fossa cubital, também no lado esquerdo.

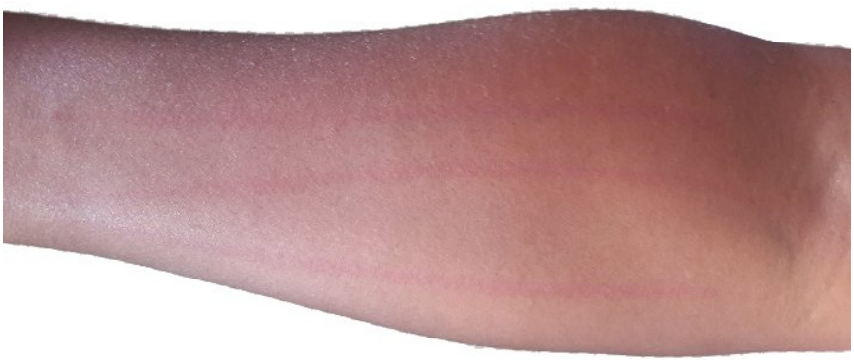

Figura 1 - Lesão dermográfica na região de antebraço direito

Exames laboratoriais de sangue previamente realizados revelaram resultados dentro dos valores de referência. A Pressão Arterial Sistêmica aferida no momento da VD revelou valores normais. Tendo em vista a normalidade dos valores de eosinófilos no hemograma, descartou-se a hipótese de processo alérgico.

Baseado nos achados clínicos e na anamnese, a hipótese diagnóstica foi de dermografismo. A fim de confirmação, foi realizado o teste de provocação, que 
consistiu na utilização de um objeto de ponta romba provocando uma pressão na pele. Alguns minutos após, observou-se o surgimento de lesões, acompanhadas de prurido, confirmando assim o diagnóstico de dermoorafismo (Fioura ?)

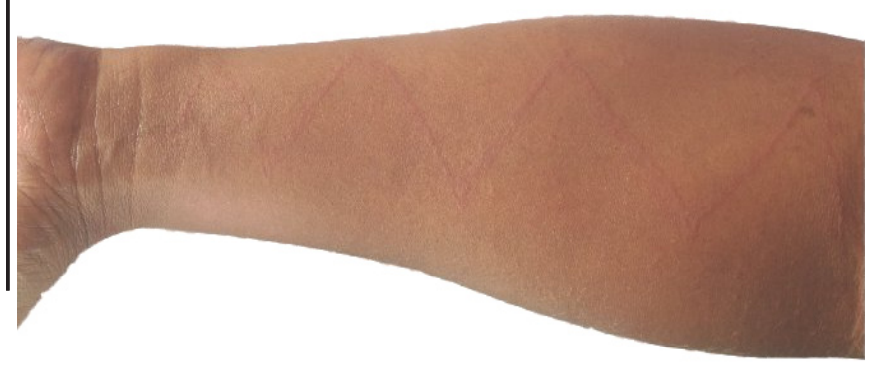

Figura 2 - Lesão dermográfica no antebraço após teste de provocação.

Foi então prescrito anti-histamínico sistêmico Loratadina $1 \mathrm{mg} / \mathrm{ml}$, com posologia de 1 comprimido a cada 24 horas por 3 dias. Decorrido este período, observou-se a regressão das lesões na pele, sem sequelas ou cicatrizes e a paciente assintomática.

A paciente foi orientada a diminuir o atrito na pele (evitando roupas justas), a evitar banhos quentes e demorados (pois o calor tende a ressecar a pele), a aplicar hidratante corporal após o banho e a também evitar estresse ou qualquer outro desencadeante.

\section{Discussão}

O dermografismo é uma doença da pele, também conhecida como uma neurodermatose, em que a pele é hiper-reativa e muito susceptível ao atrito físico ${ }^{4}$. As urticárias físicas constituem um subgrupo heterogêneo dentro das urticárias, cujos sintomas possuem duração efêmera, não ultrapassando 2 horas. No entanto, existem exceções que são as urticárias tardias de pressão, entre as quais se encontra o dermografismo ${ }^{2}$.

É prudente, diante de um caso de dermografismo, realizar uma anamnese completa buscando por possíveis fatores causais, como o uso de medicamentos. Há relatos na literatura onde a etiologia do dermografismo foi creditada ao uso do medicamento atorvastatina, indicado para dislipidemia. Geralmente a substituição da droga em questão é suficiente para a resolução do quadro de dermografismo ${ }^{7}$.

Apenas uma minoria da população com dermografismo o apresenta em graus que a levem a procurar atenção médica. Mas em alguns casos, a supressão dos sintomas pode necessitar de tratamento farmacológico, a exemplo do caso aqui relatado.

Além da pele, que é seu principal alvo, o dermografismo pode se manifestar em mucosas e gerar formas inflamadas e edemaciadas, podendo levar a um quadro mais sério com angioedema, o que não foi observado no caso aqui descrito. Algumas alterações como anafilaxia, síndromes auto-inflamatórias ou angioedema hereditário podem levar a um quadro semelhante do dermografismo com acometimento cutâneo e mucoso, indicando o diagnóstico diferencial entre o dermografismo e outras doenças ${ }^{1}$.

$\mathrm{O}$ caso relatado foi diagnosticado em paciente do sexo feminino, 46 anos, coincidindo como citado na literatura: maior prevalência de dermografismo em mulheres, a partir da segunda década de vida6. As lesões no caso limitavam-se à pele, com inexistência de angioedema. Tratou-se de um caso de dermografismo sintomático, caracterizado pelo surgimento de lesões papulosas eritematosas e pruriginosas em menos de 5 minutos, cuja duração ultrapassou 30 minutos.

O diagnóstico do dermografismo sintomático descrito neste artigo pôde ser confirmado através de teste provocativo, aplicando força que levou ao atrito cutâneo, em região anterior de antebraço, utilizandose objeto firme sem corte. Assegurou-se que a pele no local testado estivesse sem soluções de continuidade e sinais infecciosos. Os resultados foram observados após 12 minutos da aplicação da força.

Dermografismo sintomático pode também se apresentar com formas foliculares ou variantes inflamadas e edemaciadas. Dermografismo sintomático é também conhecido como urticária dermográfica, urticária factícia ou neurodermatose, e corresponde ao mais comum tipo de urticária física, estando presente em 1,5 a $5 \%$ da população ${ }^{4}$.

O dermografismo sintomático tem como principais componentes a presença de prurido e o desenvolvimento de lesões em formato linear papular após o paciente coçar a pele ou após contato direto da pele com algum objeto sólido, ou até mesmo o contato com roupas ou lençóis (que possuam alguma estrutura rígida em sua composição como costuras ou estampas em alto relevo), na paciente cujo caso aqui se relata, as lesões e o prurido tiveram início após atrito físico e se agravaram com banhos quentes e demorados. De acordo com Lima et al. (2015), banhos quentes representam fator agravante para as lesões provocadas pelo dermografismo, tendo em vista provocarem o ressecamento da pele e a intensificação do prurido.

Dermografismo sintomático já foi associado na literatura com infecções bacterianas, fúngicas, e escabiose, bem como a uso de antibiótico, infecções virais ou estresse emocional, porém na sua grande maioria dos casos é de origem idiopática6, exatamente como o caso aqui descrito. Sabe-se apenas que as reações têm como mediadora a histamina, sendo questionado o papel da Imunoglobulina (IgE) em alguns casos. Adicionalmente, pesquisadores descreveram a relação do surgimento do dermografismo em decorrência de 
fatores psicossomáticos, justificando em alguns casos, a prescrição de ansiolíticos e o acompanhamento multiprofissional, com visão diferenciada, biopsicossocial para a resolução e controle dos sintomas. Contudo, não houve, no caso relatado, indicação para atendimento psicológico nem prescrição de ansiolítico $2,3,6$.

A paciente, cujo caso aqui se relata, é portadora de dermografismo sintomático simples, com quadro persistente por mais de 6 semanas, que se inicia por meio de lesões papulares e pruriginosas, que surgem após contato físico com tempo inferior a 5 minutos e com persistência superior a 30 minutos. Por serem lesões alérgicas superficiais, o dermografismo não costuma deixar cicatrizes, desde que o paciente siga as medidas terapêuticas. Caso contrário poderá deixar cicatrizes, principalmente se ocorrerem úlceras devido à coceira intensa por parte do paciente. No caso relatado, inexistiam cicatrizes decorrentes do dermografismo.

\section{Conclusões}

O dermografismo é uma urticária física que acomete significativa parcela da população. Seu diagnóstico, eminentemente clínico, está na direta dependência de uma anamnese detalhada. A remissão dos sinais e sintomas pode, ou não, depender da prescrição de fármacos. Este relato de caso evidenciou a relevância dos médicos que atuam na Atenção Primária à Saúde na identificação da doença, instituição da adequada terapêutica e nas orientações aos portadores, que geralmente, não desenvolvem sequelas.

Alcançar bons resultados clínicos em pacientes portadores de dermografismo não é uma tarefa simples devido à etiologia multifatorial e aos agentes etiológicos, que por vezes, não podem ser eliminados ou substituídos, como as vestimentas, por exemplo. Assim, a cura da doença não é o objetivo do tratamento e sim o manejo das lesões na busca do bem-estar e qualidade de vida.

\section{Referências}

1. Powell RJ, Du Toitw GL, Siddiquez N, Leech SC, Dixonz TA, Clarkk AT et al. BSACI guidelines for the management of chronic urticaria and angiooedema. Clin Exp Allergy 2007; 37: 631-50

2. Lima SO, Rodrigues CS, Camelo-Nunes IC, Solé D. Urticárias físicas: revisão. Rev. Bras. Alerg. Imunopatol. 2008; 31(6):220-226.

3. Martins ER. Urticária e angioedema. In: Rios JBM, Carvalho LP. Alergia Clínica - Diagnóstico e Tratamento. 2.ed. Rio de Janeiro: Revinter, 2007. p.505-31

4. França AT, Valle SOR. Urticária e Angioedema: diagnóstico e tratamento. 3. ed. Rio de Janeiro: Revinter; 2014.

5. Criado RFJ, Philippi JC, Franco RS, Mello JF. Urticárias. Rev. bras. Alerg. imunopatol. 2005;28:273-83.

6. Lima EMS, Lima ICS, Coelho CDP, Lima MCS. Uma visão diferenciada no manejo do dermografismo. Braz J Allergy Immunol. 2015;3(3):77-85.
7. Adcock BB, Hornsby LB, Kimble Jenkins K. Dermographism: An adverse effect of atorvastatin. JABFP 2001;14(2): 148-151.

8. Pires JS, UeAPF, Furlani WJ, Souza PK, Rotta O. Dapsona como alternativa no tratamento de urticária crônica não responsiva a anti-histamínicos. Anais Brasileiros de Dermatologia 2008; 83(5): 413-418. 